\title{
Identidad a través de la mirada: diálogo visual con las alturas en el contexto universitario de Diseño y Artes
}

\section{Resumen}

La experiencia de investigaciones anteriores nos demuestra que mirar hacia arriba es una acción importante para devolver la atención a las manifestaciones visuales olvidadas. Pero en nuestra sociedad acelerada cada vez se mira más hacia abajo y se hace menos activa la observación del entorno. El presente artículo recoge una investigación artística que se apoya en la dimensión visual del conocimiento y la importancia de la observación activa. El objetivo principal es diseñar una experiencia educativa que nos ayude a despertar el interés por mirar hacia arriba, mediante la observación activa hacia los olvidados en las alturas y retratar la comunicación con lo observado. En este estudio trabajamos con estudiantes de Diseño y Artes Plásticas y Visuales. Mediante la implicación del docente en la construcción de una narrativa visual, se muestra un recorrido de diálogo entre la mirada, la gárgola y la identidad. Esta construcción se presenta como encuesta visual a nuestros participantes, que reflexionan y hacen suya la experiencia, produciendo sus propias narrativas. Su implicación y los resultados visuales que se muestran en este artículo nos ayudan a concluir que es posible incentivar ese interés por mirar hacia arriba y manifestarlo mediante la creación de productos visuales significativos.

\author{
Begoña Yáñez Martínez \\ Doctora en Bellas Artes \\ PDI en la Universidad Internacional \\ de La Rioja-UNIR, España. \\ Correo electrónico: \\ begona.yanez@unir.net \\ ๑ orcid.org/0000-0003-2543-7615 \\ Google Scholar
}

Recibido: marzo 12 de 2021

Aprobado: junio 16 de 2021

Key words:

educación visual, identidad, mirar hacia arriba, observación activa. 


\title{
Identity through the gaze: visual dialogue with heights in the higher education context in Design and Arts
}

\begin{abstract}
The experience of previous research has shown that looking upwards is an important action to return attention to forgotten visual manifestations. However, in the fast-paced society today, people are increasingly looking downwards and are performing fewer active observations of their environment. This article presents an artistic research based on the visual dimension of knowledge and the importance of active observation. The main objective is to design an educational experience that helps awakening the interest in looking upwards through active observation of forgotten elements in the heights and portraying the communication with what is observed. This study involved students of Design and Visual and Plastic Arts. Through the involvement of the professor in the construction of a visual narrative, a dialogue between the gaze, the gargoyle and the identity is established. This construction is presented as a visual survey to its participants who reflect on and make the experience their own, creating their own narratives. Their involvement and the visual results shown in this article help conclude that it is possible to encourage this interest in looking up and manifesting it through the creation of meaningful visual products.
\end{abstract}

Key words:

visual education, identity, looking up, active observation. 


\section{Introducción}

La experiencia que vamos a presentar en este trabajo parte de la dimensión visual del conocimiento y la observación activa de nuestro entorno como método de aprendizaje y conexión con la identidad del observador.

El objetivo general se centra en diseñar una experiencia educativa para incentivar el interés y desarrollar la capacidad de esta observación activa. Esta iniciativa se configura implicando la propia experiencia del docente, desde el trabajo con la metáfora de mirar hacia arriba y la reciprocidad de la mirada, que incide en la configuración de nuestra identidad visual. Para ello se ha llevado a cabo una propuesta de creación visual con una serie de estudiantes voluntarios de Diseño y de Artes Plásticas y Visuales, de UNIR y la Universidad Nebrija.

Para comprender mejor este punto de partida tenemos que profundizar en los aspectos que mueven la iniciativa desde la Educación Visual.

Los aspectos que vamos a trabajar en esta introducción son conceptos interconectados:

- Mirar hacia arriba. La observación activa y elevar la mirada, hacerla más relevante en nuestro aprendizaje.

- Educar la mirada. El aprendizaje a través de las imágenes, la relación coherente con el entorno y la dimensión visual del conocimiento (Arnheim, 1971; Eisner, 1995; García-Sípido, 2002).

- Diálogos visuales. La reciprocidad de la mirada, cómo nos devuelve la mirada aquello que observamos (Costa, 2007; Berger, 2016). 
- La experiencia visual y la identidad. Al mirar nos situamos en el entorno, creando conciencia de nosotros mismos (Dewey, 2008; Dondis, 2017). Son procesos de identificación y pertenencia.

La imagen es didáctica por sí misma. Esta afirmación, que podría considerarse algo atrevida, se respalda al revisar los conceptos que acabamos de ver. "El pensamiento verdaderamente productivo tiene lugar en el reino de las imágenes" (Arnheim, 1971, p. IX). Si somos capaces de enseñar a nuestros alumnos a mirar de forma activa, a observar el entorno visual que nos contempla, seremos capaces de desarrollar su potencial cognitivo (Eisner, 1991). Este es uno de los propósitos educacionales que tienen educar la mirada en general y mirar hacia arriba en particular.

Mirar hacia arriba es en sí mismo una metáfora de observar a todo aquello que pasa desapercibido cuando vamos con la cabeza baja, con la percepción limitada. Es una Ilamada a despertar el interés por observar a los olvidados y conocer mejor nuestro entorno. "La experiencia visual resulta fundamental en el aprendizaje para comprender el entorno y reaccionar ante él" (Dondis, 2017, p. 17). Estas experiencias visuales configurarán "momentos de conocimiento" que servirán de referencia en el aprendizaje, en las vivencias del observador ayudándole a "enfrentarse con la complejidad del mundo visual" (GarcíaSípido, 2003, p. 66).

Como educadores, nuestra misión es enseñar la importancia de la dimensión visual del conocimiento ya que "influimos en la configuración de la mente" (Eisner, 1991, p. 14). Educar la mirada va más allá del simple hecho de ver. Se trata de ser más conscientes de lo que vemos. Elevar la mirada es mirar con mayor profundidad a las cosas, aprehendiendo de ellas. "Ver es adquirir sentido visual a través de la experiencia" (Eisner, 1995, p. 87), "entendemos el mundo a través de las imágenes" (De Pablo y Lasa, 2015, p. 20). 
Como indica Berger (2016), aquello que observamos nos devuelve la mirada. La mirada es nuestro umbral del conocimiento y, a su vez, una herramienta de construcción de la identidad. En la mirada hay una relación entre nosotros y aquello que miramos. Miramos desde nosotros mismos. "La vista establece nuestro lugar en el mundo circundante" (p. 17). "Nuestro sistema sensorial es el responsable de que seamos capaces de establecer contacto con el mundo. Cada modalidad sensorial nos capacita para experimentar el mundo de forma diferente" (Eisner, 1991, p. 16).

El diálogo recíproco con aquello que miramos es una de las bases de la experiencia. Como nos dice Pericot (1987), "la doble direccionalidad informativa" (p. 27). En las miradas que dirigimos a nuestro entorno este nos corresponde con conocimiento e identidad, creando una relación de complicidad y pertenencia. Esta relación del mirar y ser mirados es lo que Berger (2016) Ilama la reciprocidad comunicativa entre mirar y ser vistos:

Poco después de ver, nos damos cuenta de que también podemos ser vistos. El ojo del otro se combina con el nuestro para dar plena credibilidad al hecho de que formamos parte del mundo visible. [...] La naturaleza recíproca de la visión es más fundamental que la del diálogo hablado. (p. 9)

Cuando ese diálogo visual recíproco se traduce en un producto visual estamos construyendo una forma tangible y perceptible de compartir esa comunicación. Mediante la creación de imágenes que capten esa esencia de la mirada, esa comunicación, ese mirar hacia arriba, damos voz a aquello que estamos retratando.

En la actividad artística se lleva a cabo de forma indivisible hacer, pensar y percibir, profundizando en el aprendizaje visual. No se trata solo de educar la mirada para percibir el mundo, sino también de establecer una transferencia al mundo productivo que permita crear y comprender mensajes visuales. El sentido de la vista tiene un factor innato y otro que deberá desarrollarse 
mediante el estudio para poder alcanzar una mayor eficacia en ese hacer y comprender (Dondis, 2017).

Otra relación importante en la investigación es la que tienen mirada e identidad. Esto nos lleva al desarrollo de habilidades transversales como el desarrollo de la intuición y la creatividad. El estudio de los acontecimientos visuales que van más allá de las imágenes que se conocen como artísticas, tiene relación con nuestra cotidianeidad, con una relación significativa e identitaria con nuestro entorno (Hernández, 2000).

El origen de esta propuesta reside en la experiencia vivida en el transcurso de la realización de la investigación para la obtención del doctorado (Yáñez, 2014), en la que se fotografió a las gárgolas de las catedrales españolas. Mirar hacia arriba era la herramienta principal para la obtención de las imágenes, pero también para poder ser conscientes de su existencia. Por ello, por atención conjunta, las personas que pasaban alrededor de esta situación miraban ahí donde la cámara estaba mirando.

La atención conjunta [...] refiere simplemente a mirar hacia donde alguien está mirando, y en su definición amplia incluye el inicio, la respuesta a la atención conjunta y el monitoreo de la atención del otro hacia una entidad exterior, con la suposición de que otro está mirando y experimentando algo en el mundo visual. (Elgier et al., 2017, p. 12)

En esta potencialidad de la atención conjunta se basa la hipótesis de la posibilidad de contagiar esa intención de elevar la mirada, de educarla y de darle voz a los olvidados de las alturas, a través de expresiones visuales que retraten cómo las alturas nos devuelven la mirada. 


\section{Método}

El método llevado a cabo en esta investigación es eminentemente visual en su exposición, en su desarrollo y en la búsqueda de resultados. Mediante la comunicación visual, se busca recibir una respuesta en forma de productos visuales que tengan un alto componente identitario y crítico-reflexivo.

El proceso comienza en la formación oficial desarrollada por nuestros participantes, donde se trabajan las formas de comunicación visual (Català, 2008; Martín-SanRomán, 2016; Deltell et al., 2020) y el pensamiento gráfico creativo, que se compone de pensamiento creativo, pensamiento de proyectos y descubrimiento de problemas (Barban, 2021). También se insiste en la importancia de la dimensión visual del conocimiento (García-Sípido, 2002), de la mirada crítica (Hernández, 2000) y de la alfabetización visual (Eisner, 1991; Pericot, 1987; Dondis, 2017). Sobre esa base de aprendizaje, presentamos a los participantes una propuesta creativa basada en un estudio previo sobre la propia identidad y mirada que veremos más adelante.

Este estudio se construye con un enfoque a/r/tográfico en el que el docente es a su vez investigador y artista (Irwin et al., 2017). La a/r/tografía es "una metodología en la que confluyen simultáneamente los intereses artísticos, educativos e investigadores" (Marín-Viadel y Roldán, 2019, p. 882). La experiencia artística será la base de la investigación, y las distintas interpretaciones se traducirán en múltiples experiencias particulares de reflexión visual.

Se trabaja en el ámbito de la Investigación Basada en Artes, que afirma que "en toda actividad artística hay un propósito investigador. Al tiempo que una finalidad pedagógica, en el sentido de que construyen y proyectan representaciones sobre parcelas de la realidad, que fijan maneras de mirar y de mirarse" (Hernández, 2008, p. 92). Compartir experiencias amplificará 
las posibilidades investigativas y pedagógicas de esta línea de trabajo (De Miguel, 2013).

Ser docente en asignaturas con un alto componente visual Ileva ligada esa doble vertiente de investigación-creación y enseñanza-aprendizaje. "Desde hace algunas décadas la Educación Artística se configura como un territorio especializado de investigación, situado justo en la intersección entre los problemas de las artes visuales y los problemas educativos" (Marín-Viadel, 2011, p. 212).

La forma de construir conocimiento irá ligada de forma inseparable a la creación artístico visual y, a su vez, a incentivar las creaciones de los estudiantes. La implicación en el proceso de aprendizaje mediante la interpretación y la creación, tanto por parte del docente como de los participantes, se basa en una humanización de los procesos de enseñanza que favorecen la construcción de aprendizajes significativos. El alumno es el protagonista del aprendizaje y en esta experiencia el docente está al mismo nivel, implicándose con su creación artística y sus mensajes más allá de la simple transmisión de información o la creación de productos estéticos (González y Sirvent, 2018).

Para conseguir la implicación de su observación activa se opta por seguir algunas de las condiciones para el aprendizaje de las Artes Visuales que nos presenta Eisner (2002). Es importante que se cree una conexión con la propia experiencia para que realmente se produzca un aprendizaje significativo. Mediante la muestra de ejemplos visuales construidos y la explicación del recorrido de la narrativa visual, se ofrece una canalización de su expresividad habitualmente desbordada. "La creatividad se beneficia de las limitaciones de libertad" (Eisner, 2002, p. 49). Es necesario que se desarrollen conexiones entre lo que se les muestra en el ejemplo y sus propias inquietudes. La enseñanza de 
las Artes Visuales favorece "la transferencia de conocimientos entre diferentes campos" (Eisner, 2002, p. 52).

Hacerles reflexionar sobre aquello que se ha dejado de observar, que no recibe la atención adecuada, es el punto de partida. "La calidad del pensamiento artístico del estudiante determina la calidad del trabajo artístico" (Eisner, 2002, p. 48). Para un correcto desarrollo de su experiencia posterior, primero les explicamos qué son los relegados al margen y posteriormente se presentará la narrativa visual, que en este caso particular gira en torno a la gárgola, por su relación con las investigaciones de la autora y por sus sinergias para el aprendizaje de mirar hacia arriba.

\section{Relegados al margen}

Como si se tratara de un acertijo filosófico, aquello que no miramos es como si no existiera. De esta manera, en la Historia del Arte ha habido una serie de elementos que podemos considerar olvidados. A estos, Monteira et al. (2009) los denominan los relegados al margen. Hablamos de gárgolas, canecillos, misericordias, marginalia, etc. Este aspecto es el que configurará a qué mirar y desde dónde construir la identidad.

En la presentación inicial de la propuesta a los participantes, se les plantean varias opciones en cuanto a lo oculto o lo desconocido (Figura 1), como seres fantásticos (representados en la imagen por el Dragón), mitología (Centauro), mundo del cine (Darth Vader) o de la literatura (Cthulhu). 

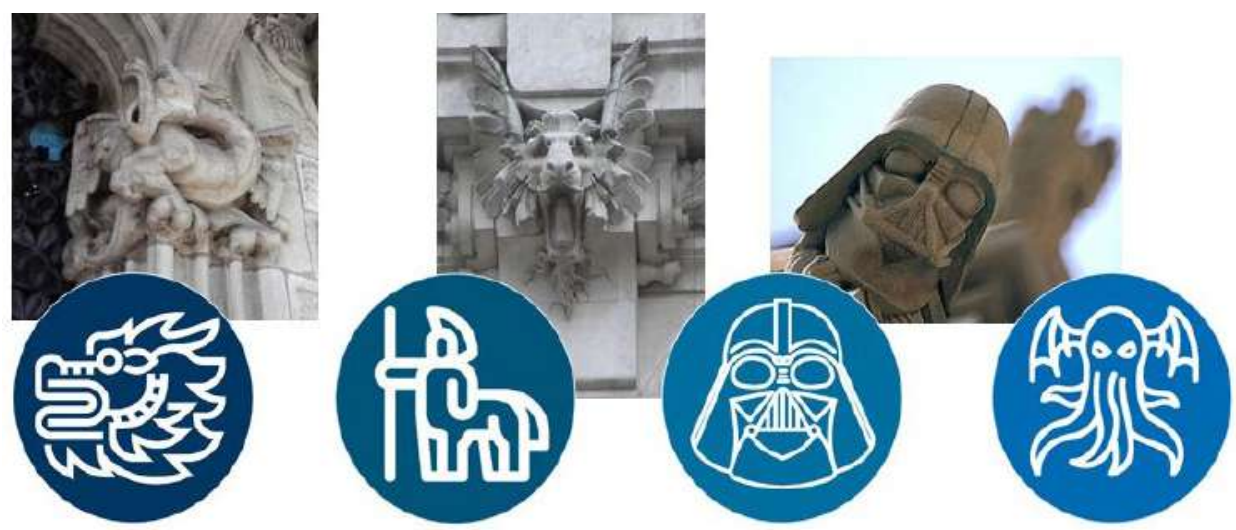

Figura 1. Ejemplos presentados a los alumnos de relegados al margen. Fuente: fotografías 1 y 2 de la autora; Darth Vader, Jay Hall Carpenter (1980):

https://cathedral.org/what-to-see/exterior/vader/ - Iconos de Flaticon.

El grotesco de Darth Vader de la catedral de Washington encierra una historia significativa en torno a esta reciprocidad de la que hablamos. Se llevó a cabo en 1980 por el escultor Jay Hall Carpenter, que dio vida a los dibujos de un concurso infantil de la catedral. "El ganador del tercer lugar fue Christopher Rader de Kearney, Nebraska, con su dibujo de Darth Vader" (Carpenter, 2015, s.p.). Actualmente se encuentra en la torre noroeste de la catedral y resulta un elemento difícil de observar por su posición y por la altura.

Nuestra sociedad de consumo rápido y falta de atención va relegando al margen cada vez a más manifestaciones visuales, por lo que educar la mirada e incentivar la observación activa tiene una doble intención educativa. 


\section{Narrativa visual}

Los tres pilares que mueven la investigación identitaria inicial —ejemplo que se presentó a los estudiantes_ - son la mirada, la gárgola y la identidad (Figura 2). Para ser coherente la relación de estos tres pilares se presentó en forma de narrativa visual. La intención es compartir y contagiar el interés por mirar hacia arriba, despertando la atención por lo oculto, lo olvidado, lo escondido. Presentamos como olvidado la gárgola, pero se anima a los alumnos a sustituirla por aquello con lo que se identifiquen más.

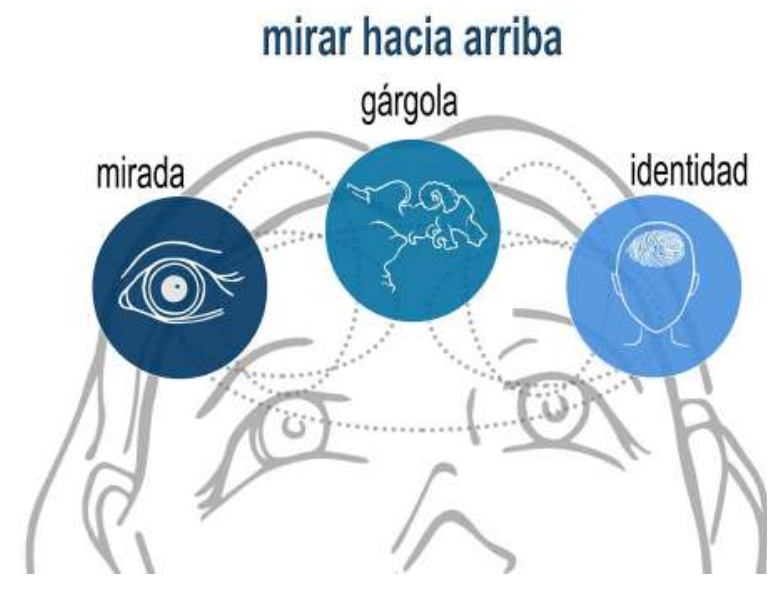

Figura 2. Los tres pilares del origen de la experiencia: mirada, gárgola e identidad. Fuente: Autora (2020)

Para construir el recorrido y la encuesta visual se llevó a cabo un vídeo que incluía las imágenes que iban ilustrando esta conexión de los tres pilares. Este recorrido constaba de las paradas que explicamos a continuación. 
1. Diálogo directo con la gárgola. La observación directa, un diálogo cara a cara (Figura 3).

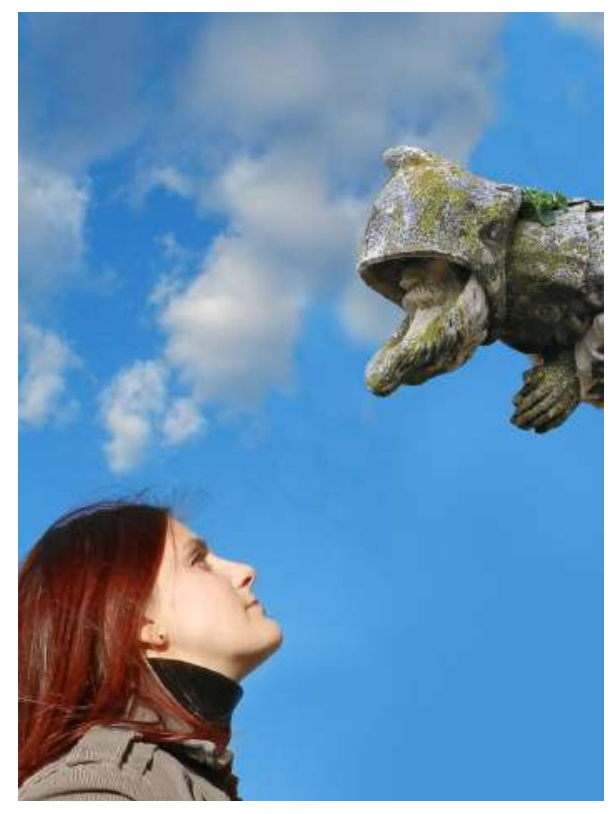

Figura 3. Diálogo directo con la gárgola. Fuente: Autora (2019)

2. Mirada a través de la cámara. La forma de captarlas es la mirada técnica (Berger, 2016) que se produce a través de la cámara de fotos. En la imagen del recorrido se mostraba un fotomontaje en el que la gárgola estaba integrada dentro del objetivo de la cámara como metáfora del diálogo entre ellas. 
3. Creación artística. Esta observación y análisis nos lleva a la investigación artística, siendo la gárgola —especialmente las gárgolas españolasel motivo de numerosos dibujos e ilustraciones (Yáñez, 2019).

4. La gárgola y la mirada. En esta sección comenzamos la conexión ojogárgola, en fotomontajes que ilustran esa reciprocidad de la mirada (Figura 4).

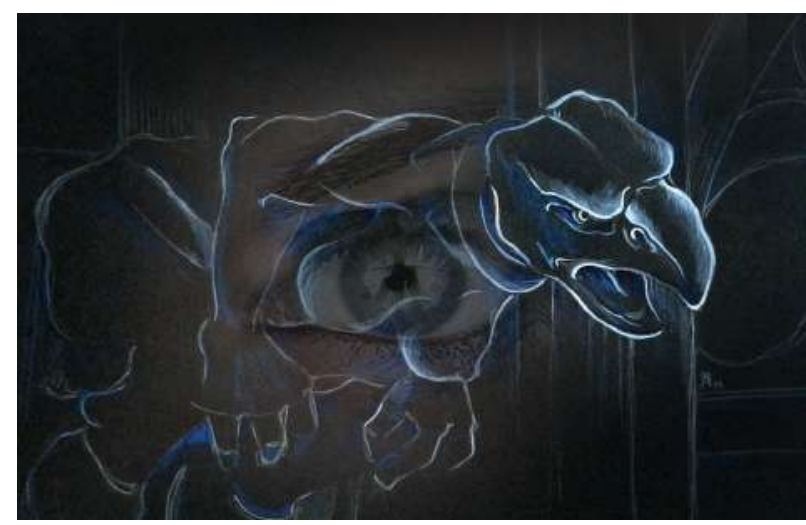

Figura 4. Reciprocidad en la mirada a través de la creación artística. Fuente: Autora (2019).

5. Interiorizar la gárgola. La gárgola integrada en el iris, igual que previamente estuvo en el objetivo de la cámara. Ahora forma parte de nuestra mirada natural.

6. La gárgola y la identidad. Por último, la identidad (Figura 5). Este diálogo nos lleva a una conexión inseparable que conformará un proceso identitario. 


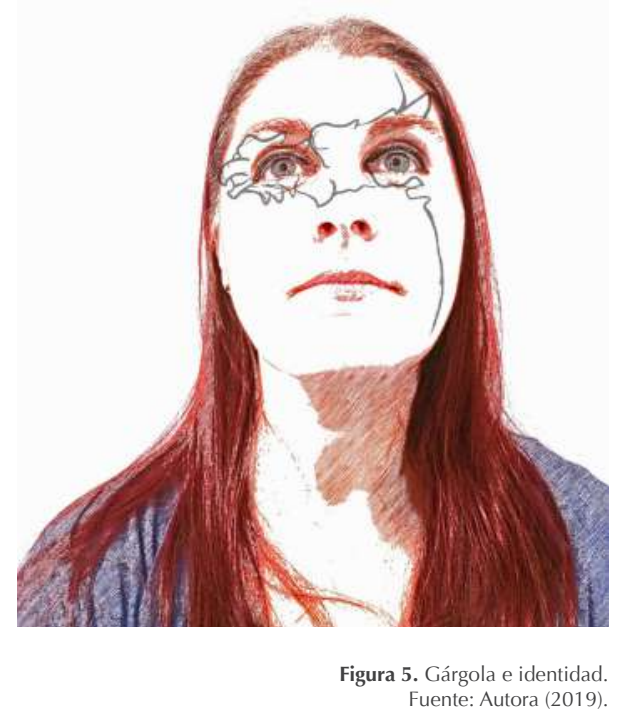

Una vez presentada la narrativa se pide a los participantes que profundicen en la idea y reflexionen, desde su experiencia, sobre estos olvidados y cómo entablar un diálogo visual con ellos.

A fin de entender lo estético en sus formas últimas y aprobadas, se debe empezar con su materia prima; con los acontecimientos y escenas que atraen la atención del ojo y del oído del hombre despertando su interés y proporcionándole goce mientras mira y escucha. (Dewey, 2008, p. 5)

Se propone como técnica el fotomontaje, pero queda abierta a las necesidades comunicativas de cada uno. El punto de partida es la observación y, a partir de la mirada, construir las ideas que se llevarán a sus imágenes. "Uno de los usos principales de la mirada consiste en ayudar a la mente a enfrentarse con la 
compleja imagen del mundo, más allá del mero registro de imágenes ópticas" (García-Sípido, 2003, p. 62). La mirada técnica que nos ofrecen la fotografía y las posibilidades del fotomontaje también van más allá del simple registro mecánico de la realidad (Berger, 2016). Nos permiten transmitir sentimientos, emociones y conceptos evocadores que inviten a la reflexión (McGowan, 2007; Alcalá, 2021).

\title{
Resultados
}

De acuerdo con Marín-Viadel y Roldán (2019):

\begin{abstract}
Un informe de investigación puede ser evocativo, imaginativo, expresivo, empático y metafórico, y puede estar escrito de manera que no haya un significado exactamente literal de los resultados porque lo que se busca es provocar una nueva experiencia, una nueva forma de experimentar y de comprender el problema. (p. 886)
\end{abstract}

Lo que se busca, tanto en la realización de la investigación visual como en la propuesta creativa, es transmitir la observación activa hacia los olvidados y retratar la comunicación con lo observado.

Los resultados de la investigación son a su vez los resultados de nuestros participantes. Cada interpretación de aquello que nos observa desde las alturas ha enriquecido el proyecto y lo ha ampliado hacia nuevas significaciones, conservando el potencial simbólico en combinación con la mirada y la identidad.

Comenzamos por aquellas propuestas que han mantenido a la gárgola como elemento con el que dialogar.

Ondiz nos presenta dos caras de una misma idea (Figura 6). La primera muestra el poder de las redes sociales y cómo mostramos una identidad construida, 
y la segunda trae a la realidad la relación poniéndose al mismo nivel que la gárgola, como ella misma dice, como iguales e inmóviles para la fotografía.

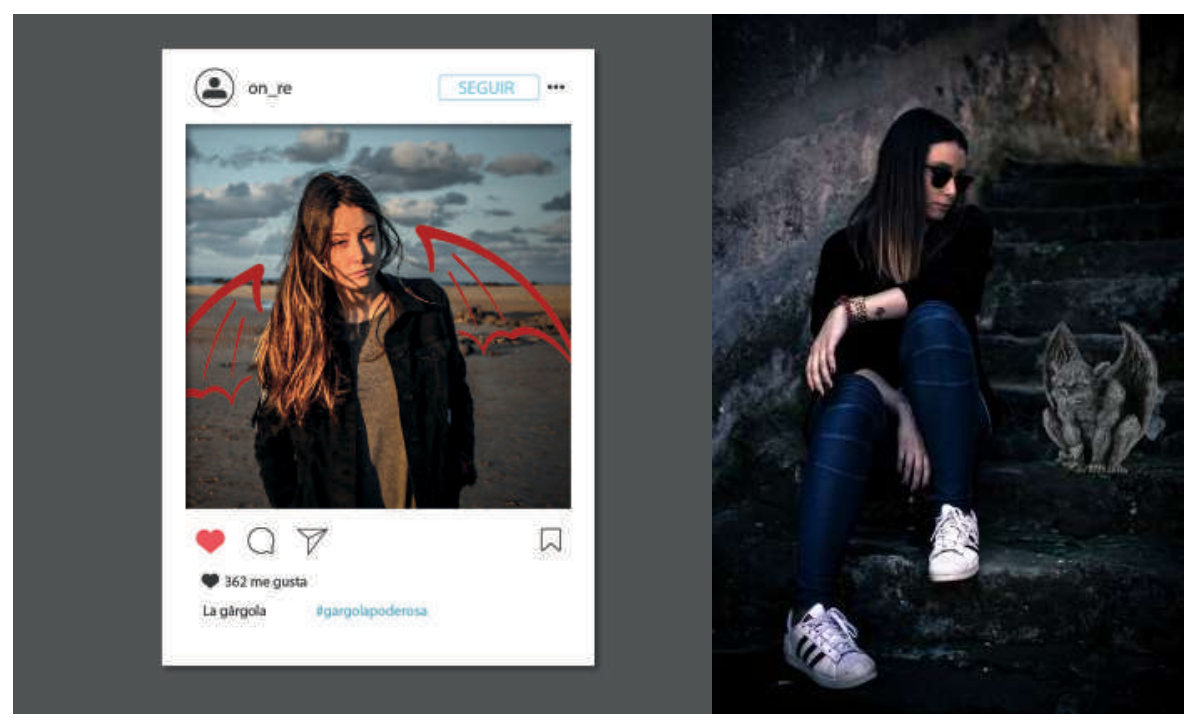

Figura 6. La gárgola poderosa (izquierda). Equidad con la gárgola (derecha). Fuente: Ondiz Renedo (2019).

Mónica (Figura 7) Ileva a su terreno la propuesta, en la línea de la ilustración naif o tipo cómic con la que se siente cómoda, reflejando el ensimismamiento, la pasión y la interacción entre el arte y el observador. Todo ello teñido de una mirada de fantasía, feminidad y evocación. 


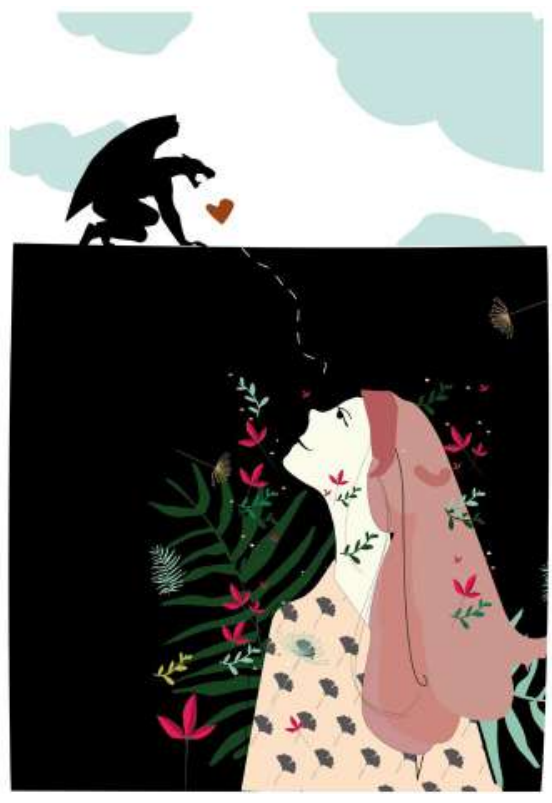

Figura 7. Diálogo de la feminidad con la gárgola (ilustración inspirada en la quimera del Puente del Reino en Valencia).

Fuente: Mónica Martínez (2019).

Continuamos esta nueva narrativa construida a través del recorrido por las participaciones y dejamos a la gárgola, pero no la mirada a las alturas, ya que es uno de los temas que apasionan a Rosa Ana. En sus imágenes (Figura 8) mantiene los pilares de la investigación y los hace suyos. Vemos una atención por los cielos con nubes y las esculturas en lo alto de los edificios. La identidad se refleja en el tratamiento de la imagen, la orientación norte de los cielos y la representación de su mirada en una hipérbole de unas medias lunas que se producen ópticamente en cada uno de sus ojos. 


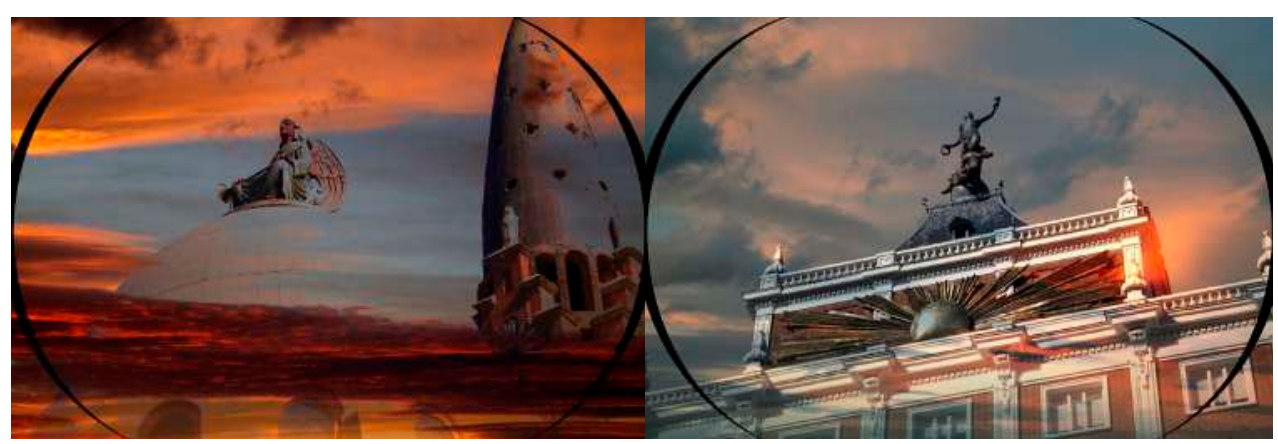

Figura 8. Orientación norte, ángel (izquierda). Orientación norte, ocaso (derecha). Fuente: Rosa Ana Martínez (2019).

María también mira a las alturas y tiene un diálogo con los monumentos de Huelva (Figura 9) tratando de recuperar la historia de la ciudad narrada en estas representaciones. Ella las describe como "recuerdo vivo de la grandeza histórica que un día aconteció en este lugar" del que partiera Cristóbal Colón en su primer viaje. De entre ellos, destacamos su diálogo con el Monumento a la Fe Descubridora. 

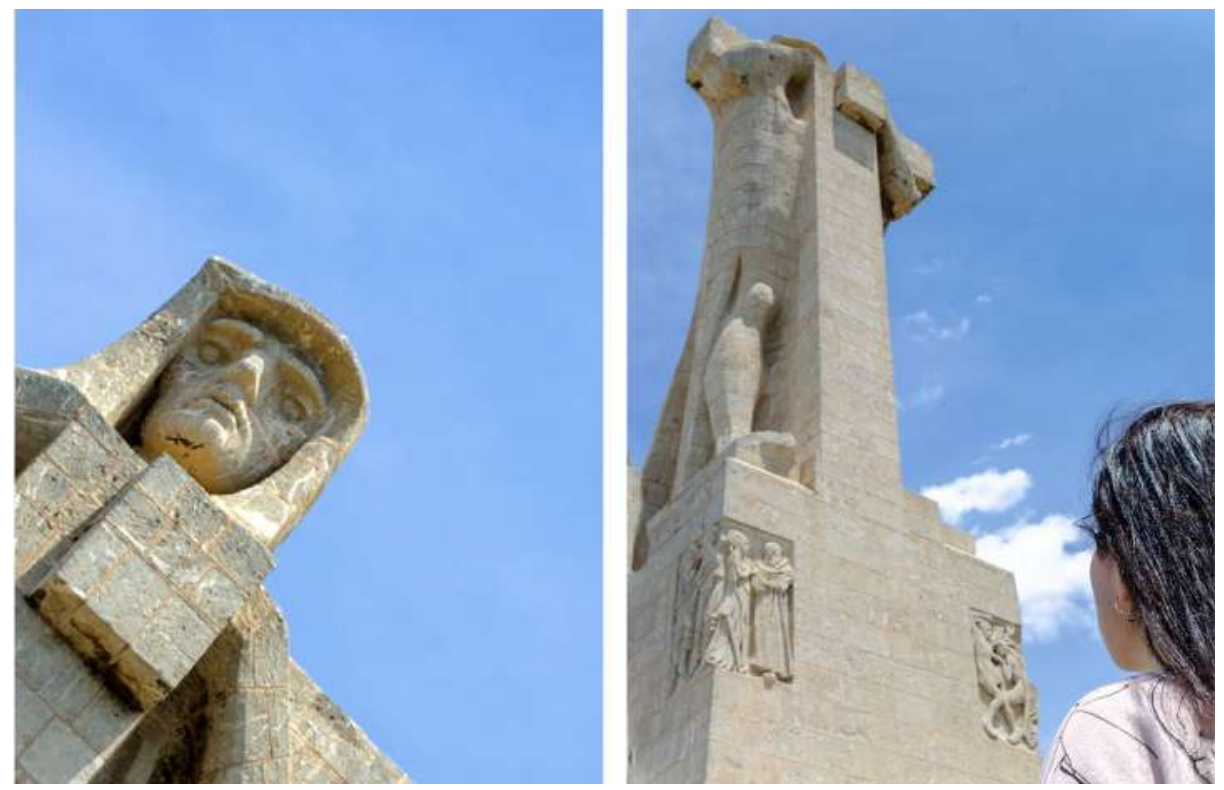

Figura 9. Diálogo de María con el Monumento a la Fe Descubridora en Huelva. Llevado a cabo por la escultora G. Withney con la colaboración del Columbus Memorial Fundation. Donado por Estados Unidos en 1929 Fuente: María Moreno Tamayo (2019)

Juanma conecta la mirada hacia arriba con dar visibilidad a dos motivos que siempre están sobre nuestras cabezas, pero de los que hemos normalizado su situación y apenas reparamos en ellos. Desde una perspectiva más cercana a la filosofía, acerca la construcción de la naturaleza a "la determinación correlativa del sentido de la vida cultural (o espiritual)" (Venebra, 2019, p. 122). Es una conexión de la naturaleza real y el entorno construido con 
nuestra identidad vital (Figura 10). Las ramas de los árboles, asociadas a una necesidad biológica que representa con el corazón, y las torres eléctricas, que transmiten la electricidad unida inseparablemente a nuestro día a día.

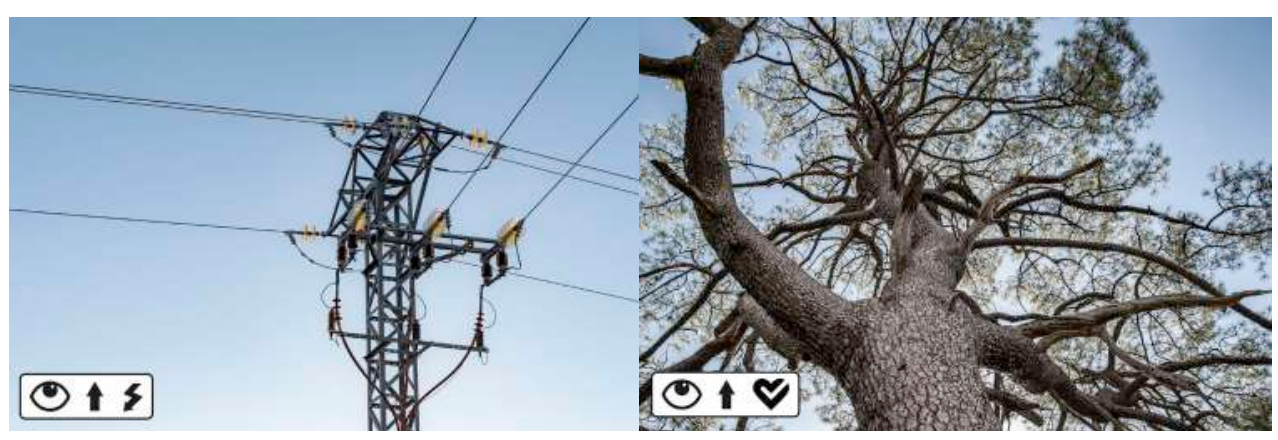

Figura 10. Mirar hacia arriba. Identidad vital, electricidad (izquierda). Mirar hacia arriba. Identidad vital, árbol (derecha). Fuente: Juan Manuel Ruiz (2019)

Cerrando los trabajos seleccionados miramos hacia la inclusión. Los derechos humanos definen "la discriminación como toda forma de exclusión, distinción o estigmatización" (Montenegro et al., 2020, p. 10). Alba (Figura 11) tiene un diálogo visual con la Luna como olvidada de nuestra cultura actual cuando tuvo un lugar importante en las mitologías y leyendas populares en todo el mundo. Esta relación mágica y mística lleva a Alba a profundizar en su propia identidad, a mirar a la vez hacia arriba y hacia adentro de sí misma, buscando ese poder de lo femenino, de la Diosa Madre, como luz en la noche, construyendo un diálogo visual cósmico entre la Luna y su mirada. 

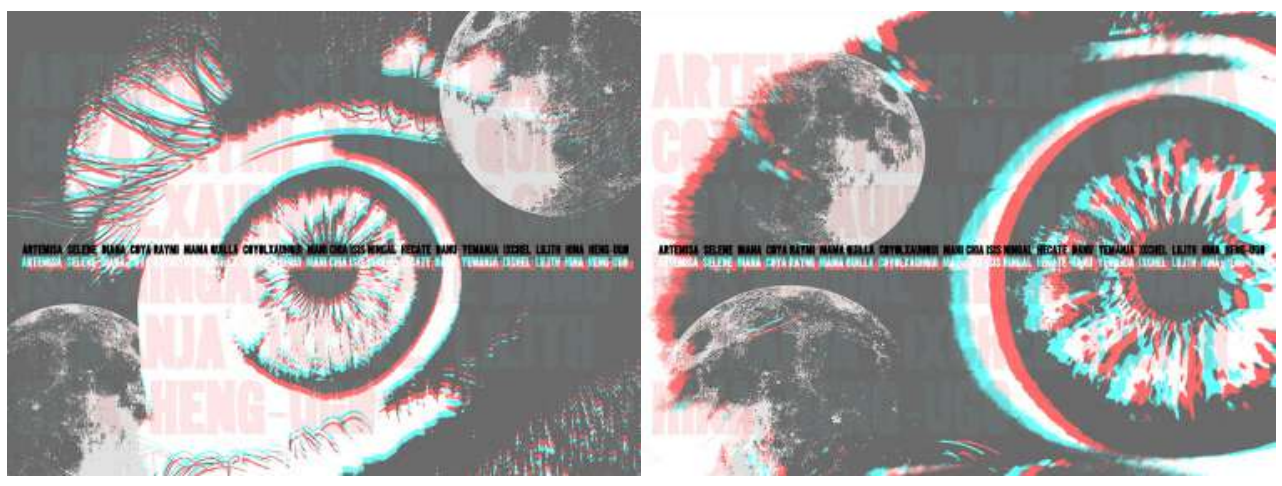

Figura 11. El diálogo cósmico entre la mirada y la Luna. Fuente: Alba Aubanell (2019).

Cada mirada, cada interpretación y cada identidad han enriquecido de una forma maravillosa los tres pilares que se lanzaban a los alumnos en la propuesta, dotando de un nuevo significado global a la metáfora del mirar hacia arriba. La narrativa construida con el recorrido por estos trabajos de los estudiantes completa y complementa la que hemos visto en método, construyendo con ella un nexo artístico, evocador y emocional, y reafirmando la magia del proceso de enseñanza-aprendizaje cuando todos participamos al mismo nivel: la bidireccionalidad del conocimiento. Usando las palabras de Flusser, "tal relación espacio-tiempo reconstruida a partir de la imagen es propia de la magia, donde todo se repite y donde todo participa de un contexto pleno de significado" (citado en Costa, 2007, p. 26). 


\section{Conclusiones}

La intención de todo el proyecto reside en pasar de ser meros observadores de la realidad a constructores de mensajes visuales que ayuden al conocimiento de dicha realidad. Contagiar el interés por mirar hacia arriba, dejarnos observar por las alturas, comienza un diálogo de aprendizaje mutuo que permite la apertura a una dimensión visual del conocimiento. Esta es la esencia del objetivo general de la investigación, que se ha cumplido a través de la experiencia inicial del docente en la construcción de la propia narrativa visual, pero principalmente a través de los procesos y resultados del alumnado.

En el caso de las participaciones que comparten la atención hacia la gárgola, como en el caso de Ondiz o Mónica, vemos una inspiración directa en las imágenes que se presentaron como encuesta visual (figuras, 3, 4 y 5). A pesar de esta conexión más directa, la identidad de cada una se ve en la elección de sus estilos personales de comunicación visual.

En las relaciones directas con las alturas, mediante la necesidad de llevar la atención a representaciones visuales que requieren mirar hacia arriba, como en los casos de María y Rosa Ana, vemos también esa intencionalidad comunicativa hacia mostrar cómo la miran ellas de forma particular. Hay una relación de identidad patrimonial, en el caso de María, y una materialización del modo de ver de Rosa Ana.

Juanma y Alba tienen una visión más conceptual y filosófica. Cada uno con su estilo personal, Juanma más de diseño, minimalista y con mensajes icónicos; y Alba con una delicadeza especial hacia mirar mucho más allá y comprender perfectamente la intención del proyecto con unas imágenes que son mirada e identidad. 
Podemos concluir que mirar hacia arriba es contagioso, por la curiosidad de la gente por saber qué está pasando ahí donde otro está mirando. Mediante la experiencia de años de retratar la gárgola ha habido muchas situaciones en las que la gente se paraba al lado de la cámara y se ponían a observar aquello que se estaba fotografiando (Figura 12). Es agradable pensar que, esas personas, han abierto los ojos a aprender de las alturas. No podemos demostrar si habrán seguido haciéndolo más allá de ese momento de contagio por atención conjunta, pero sí queda latente la transferencia del interés en este caso concreto con el alumnado de Diseño y Artes Plásticas y Visuales. Esto se ha demostrado con su participación voluntaria en este proyecto, con una implicación que es de agradecer y valorar, y con una profundización en la mirada transmitida a través de imágenes de calidad.
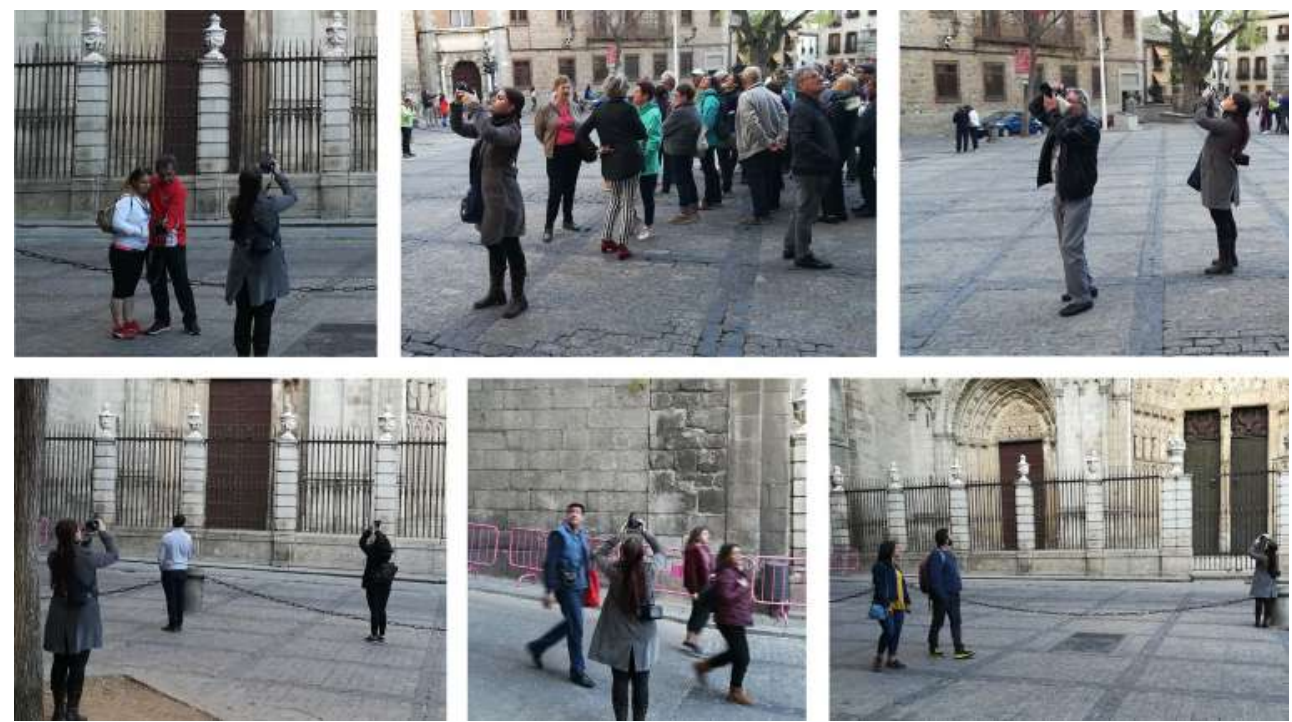

Figura 12. Conclusiones visuales. Contagiando mirar hacia arriba. Fuente: Autora (2019) 


\section{Referencias}

Alcalá, F. (2021). Las imágenes de Rostros y Lugares (2017). Una reflexión desde el documental performativo y los estudios visuales. Fotocinema. Revista científica de Cine y fotografía, 22, 331-349. https://doi.org/10.24310/Fotocinema.2021.vi22.11728

Arnheim, R. (1971). El pensamiento visual. Psicología del ojo creador. Alianza.

Barban, R. (2021). Creative Graphic Thinking and Contemporary Graphic Representation. En D. Raposo, J. Neves, J. Silva, L. Correia y R. Dias (Eds.), Advances in Design, Music and Arts. EIMAD 2020. Springer Series in Design and Innovation, vol. 9 (pp. 3-12). Springer, Cham. https://doi.org/10.1007/978-3-030-55700-3_1

Berger, J. (2016). Modos de ver. Gustavo Gili.

Carpenter, J. H. (16 de diciembre de 2015). Darth Vader and Other Stars. http://jayhallcarpenter. com/darth-vader-and-other-stars/

Català, J. (2008). La forma de lo real. Introducción a los estudios visuales. UOC.

Costa, J. (2007). Diseñar para los ojos. Costa Punto Com.

De Miguel, L. (2013). La investigación artística a través de la investigación basada en las artes: narrando una historia, compartiendo experiencias. Revista Sonda: Investigación y Docencia en las Artes y Letras, 2, 61-84. https://revistasonda.upv.es/2013_Art\%c3\%adculo_DE_ MIGUEL_Laura.pdf

De Pablo, F. y Lasa, M. (2015). ¡Dibújalo! Innova, crea y comunica de manera visual. LID.

Deltell, L., Claes, F., McGowan, N. M., Mendieta, E., Bertella, F., Gañán, R., Alfeo, J. C., Sánchez, J. L., Díaz, S., Pitters, L., Revuelta, M. J. y Vega, C. (2020). Creación de contenidos fotográficos y audiovisuales en Wikipedia [Proyecto de Innovación Docente]. UCM.

Dewey, J. (2008). El arte como experiencia. Paidós Estética.

Dondis, D. A. (2017). La sintaxis de la imagen. Introducción al alfabeto visual. Gustavo Gili.

Eisner, E. W. (1991). Reflexiones acerca de la alfabetización. Arte, Individuo y Sociedad, 4, 9-22. https://revistas.ucm.es/index.php/ARIS/article/view/ARIS9192110009A

Eisner, E. W. (1995). Educar la visión artística. Paidós. 
Eisner, E. W. (2002). Ocho importantes condiciones para la enseñanza y el aprendizaje en las artes visuales. Arte, Individuo y Sociedad, 14 (Anejo 1), 47-55. https://revistas.ucm.es/ index.php/ARIS/article/view/ARIS0202110047A

Elgier, A. M., Gago, L. G., Clerici, G., Tortello, C. y Azzollini, S. C. (2017). Seguimiento del gesto de señalar y de la mirada en estadios tempranos del desarrollo. Apuntes de Ciencia \& Sociedad, 7(1), 11-20. https://doi.org/10.18259/acs.2017003

García-Sípido, A. (2002). Educar la mirada: propuesta de una dimensión visual en el conocimiento del entorno: guía didáctica. UNED.

García-Sípido, A. (2003). Saber ver, una cuestión de aprendizaje. La educación visual a debate. Arte, Individuo y Sociedad, 15, 61-72. https://revistas.ucm.es/index.php/ARIS/article/view/ ARIS0303110061A

González, M. R. y Sirvent, I. (2018). Experiencia artístico-colaborativa para el desarrollo de la mirada crítica en el aula: El Laboratorio de la Mirada. Observar. Revista Electrónica de Didáctica de las Artes, 12, 20-38. https://www.observar.eu/index.php/Observar/article/ view/94

Hernández, F. (2000). Educación y Cultura Visual. Octaedro.

Hernández, F. (2008). La investigación basada en las artes. Propuestas para repensar la investigación en educación. Educatio Sig/o XXI, 26, 85-118. https://revistas.um.es/educatio/ article/view/46641

Irwin, R. L., Golparian, S. y Barney, D. T. (2017). A/R/Tografía como metodología para la investigación visual. En R. Marín y J. Roldán (Coords.), Ideas visuales: Investigación basada en artes e investigación artística (pp. 134-164). Universidad de Granada.

Marín-Viadel, R. (2011). La Investigación en Educación Artística. Educatio Siglo XXI, 29(1), 211230. https://revistas.um.es/educatio/article/view/119951

Marín-Viadel, R. y Roldán, J. (2019) A/r/tografía e Investigación Educativa Basada en Artes Visuales en el panorama de las metodologías de investigación en Educación Artística. Arte, Individuo y Sociedad 31(4), 881-895. https://dx.doi.org/10.5209/aris.63409

Martín-SanRomán, J. (2016). Comunicación Visual. Centro de Estudios Financieros.

McGowan, N. (2007). El camino de los ingleses. Fotografiar los recuerdos y los pensamientos. Cameraman: Revista técnica cinematográfica, 7, 6-12. 
Monteira, I., Muñoz, A. B. y Villaseñor, F. (2009). Relegados al margen: marginalidad y espacios marginales en la cultura medieval. CSIC.

Montenegro, M. Herrera, L. C. y Torres-Lista, V. (2020). Los Derechos de las personas LGBTIQ+, agenda de género y las políticas de igualdad. ENCUENTROS. Revista de Ciencias Humanas, Teoría Social y Pensamiento Crítico, 11, 9-23. http://doi.org/10.5281/zenodo.3687275

Pericot, J. (1987). Servirse de la Imagen. Ariel.

Venebra, M. (2019). Naturaleza y naturalidad de la experiencia. Crítica y fundamentación fenomenológica del conocimiento científico. Tópicos, Revista de Filosofía, 56, 119 - 143. https://doi.org/10.21555/top.v0i56.979

Yáñez, B. (2014). La gárgola gótica como objeto de estudio. Proyección sobre la cultura actual, una experiencia didáctico-visual significativa. Publicia.

Yáñez, M. B. (2019). Mira hacia arriba. Investigación artística en torno a la gárgola española. En E. M. Pérez, E. Martínez y F. C. Silva dos Santos (Eds.), IMAGEN [N] VISIBLE. IV Congreso Internacional de Investigación en Artes Visuales. ANIAV 2019 (pp. 741-746). UPV. http:// dx.doi.org/10.4995/ANIAV.2019.9064

Cómo citar: Yáñez Martínez, B. (2021). Identidad a través de la mirada: diálogo visual con las alturas en el contexto universitario de Diseño y Artes. Revista KEPES, 18(24), 171-196.

https://doi.org/10.17151/kepes.2021.18.24.7 